\title{
Pain catastrophizing, but not injury/illness sensitivity or anxiety sensitivity, enhances attentional interference by pain
}

Citation for published version (APA):

Vancleef, L. M. G., \& Peters, M. L. (2006). Pain catastrophizing, but not injury/illness sensitivity or anxiety sensitivity, enhances attentional interference by pain. The Journal of Pain, 7(1), 23-30. https://doi.org/10.1016/j.jpain.2005.04.003

Document status and date:

Published: 01/01/2006

DOI:

10.1016/j.jpain.2005.04.003

Document Version:

Publisher's PDF, also known as Version of record

\section{Document license:}

Taverne

Please check the document version of this publication:

- A submitted manuscript is the version of the article upon submission and before peer-review. There can be important differences between the submitted version and the official published version of record.

People interested in the research are advised to contact the author for the final version of the publication, or visit the DOI to the publisher's website.

- The final author version and the galley proof are versions of the publication after peer review.

- The final published version features the final layout of the paper including the volume, issue and page numbers.

Link to publication

\footnotetext{
General rights rights.

- You may freely distribute the URL identifying the publication in the public portal. please follow below link for the End User Agreement:

www.umlib.nl/taverne-license

Take down policy

If you believe that this document breaches copyright please contact us at:

repository@maastrichtuniversity.nl

providing details and we will investigate your claim.
}

Copyright and moral rights for the publications made accessible in the public portal are retained by the authors and/or other copyright owners and it is a condition of accessing publications that users recognise and abide by the legal requirements associated with these

- Users may download and print one copy of any publication from the public portal for the purpose of private study or research.

- You may not further distribute the material or use it for any profit-making activity or commercial gain

If the publication is distributed under the terms of Article $25 \mathrm{fa}$ of the Dutch Copyright Act, indicated by the "Taverne" license above, 


\title{
Pain Catastrophizing, but not Injury/llIness Sensitivity or Anxiety Sensitivity, Enhances Attentional Interference by Pain
}

\author{
Linda M. G. Vancleef and Madelon L. Peters \\ Department of Medical, Clinical and Experimental Psychology, Maastricht University, Maastricht, The Netherlands.
}

\begin{abstract}
Pain draws on attentional resources, thereby disturbing the pursuit of ongoing activities. Several studies have made use of the primary task paradigm to study the disruptive function of pain on attention. In this paradigm, participants perform an attentionally demanding task, while they are occasionally distracted by mild electrical stimulation. Deterioration in task performance (in terms of speed and accuracy) is then taken as an index of attentional interference. One major finding with this paradigm was that pain catastrophizing enhances attentional interference. The current study aimed to replicate this finding and to explore the possible influence of anxiety sensitivity and injury/illness sensitivity on attentional interference. Healthy volunteers $(n=48)$ performed an auditory discrimination task and were thereby occasionally distracted by low electrocutaneous stimulations. The performance on the discrimination task was subsequently related to participants' scores on the Pain Catastrophizing Scale, the Anxiety Sensitivity Index, and the Injury/illness Sensitivity Index. We were unable to demonstrate an association of either injury/illness sensitivity or anxiety sensitivity with attentional interference. Results did, however, confirm the finding that pain catastrophizing enhances attentional interference.

Perspective: The present study showed that pain disrupts ongoing activities. This effect is enlarged in those with high levels of pain catastrophizing and is related to the threatening nature of pain stimuli. The role of anxiety sensitivity and injury/illness sensitivity seems to differ from the role of catastrophizing and needs further research.
\end{abstract}

(c) 2006 by the American Pain Society

Key words: Injurylillness sensitivity, anxiety sensitivity, pain catastrophizing, pain, attentional interference.

A nxiety sensitivity (AS) is defined as the heightened sensitivity or fear of anxiety sensations (eg, heart palpitations) that arises from the belief that these sensations will lead to harmful somatic, psychological, or physical consequences. ${ }^{25}$ AS has been suggested to play a role in the development and maintenance of various acute and chronic pain-related conditions, such as headaches, gastrointestinal pain, menstrual pain, asthma, low back pain, and musculoskeletal pain. ${ }^{2}$ Studies in both clinical and nonclinical populations have demonstrated the association between AS levels and pain related variables. AS was found to be associated with

Received March 9, 2005; Revised April 15, 2005; Accepted April 21, 2005. Supported by a grant from the Netherlands Organisation for Scientific Research (NWO) with grant no. 015-001-050.

Address reprint requests to: Linda Vancleef, MSc, Department of Medical, Clinical and Experimental Psychology, Maastricht University, PO Box 616, 6200 MD Maastricht, The Netherlands. E-mail: L.Vancleef@dmkep. unimaas.nl

$1526-5900 / \$ 32.00$

(C) 2006 by the American Pain Society

doi:10.1016/j.jpain.2005.04.003 elevated fear of pain, a heightened reported cognitive disruption by pain, and heightened analgesic use in pain patients. ${ }^{1}$ In a nonclinical population, high levels of AS were associated with decreased pain threshold and more self-reported pain in response to a cold pressor task, ${ }^{17,19}$ and AS proved to be a stronger predictor of cold pressor pain than fear of pain. ${ }^{15}$ Moreover, AS might be related to cognitive biases for physically threatening and painrelated material. ${ }^{18,29}$ By using a dot-probe task, Keogh et $\mathrm{al}^{18}$ found that pain-free volunteers high in AS exhibited an increased attentional bias toward physically threatening material. In a subsequent study, participants scoring high on AS also exhibited an increased interpretational bias specifically for pain-related situations, which, in addition, mediated the relation between AS and pain threshold in the cold pressor test. ${ }^{17}$

Thus, evidence is accumulating that AS influences the way people react to pain and thereby might be a potential vulnerability factor for chronic pain. However, recently it has been suggested that another personality 
trait, namely injury/illness sensitivity (IS), might play an equally or even more important role in determining someone's reaction to pain. ${ }^{16}$ According to the expectancy model of Reiss, ${ }^{24}$ three fundamental fears (also called sensitivities) can be distinguished, ie, AS, IS, and fear of negative evaluation. These fundamental fears might underlie all common fears that we encounter in our daily society (eg, fear of heights, fear of animals) and can be proposed to explain various psychopathologic conditions (eg, panic disorder, blood phobia, social phobia). ${ }^{31}$ The fundamental fears themselves might in turn be nested within the higher order factor of trait anxiety. By administering measures of fundamental fears, common fears, and trait anxiety to 100 community volunteers, Taylor $^{31}$ was able to demonstrate that the 3 fundamental fears are indeed factorially distinct and minimally intercorrelated and explain substantial proportions of variance in several common fears, as well as in trait anxiety.

Although this study provided evidence for IS as a distinct fundamental fear, its relation to common fears and specific forms of psychopathology has, in contrast to AS, remained largely unexplored. It was only recently that interest in IS as a potential vulnerability factor for chronic pain has arisen. Presenting an adapted version of the hierarchical model of fundamental fears, Keogh and Asmundson ${ }^{16}$ have proposed that IS might be a higher order factor of the common fear of pain and pain catastrophizing. Vancleef et al (submitted for publication) tested the association between the 3 fundamental fears and other pain-related variables in a correlational study. Results showed that both AS and IS were correlated with several pain measures, but that IS was a better predictor of pain catastrophizing and fear of pain than AS. Furthermore, IS was found to be associated with a heightened fearfulness of an impending pain stimulus before the actual stimulus presentation, whereas this heightened anticipatory fearfulness could not be established for AS (Vancleef et al, submitted for publication).

The present study further examined the putative role of AS and IS on pain responses in pain-free volunteers. More specifically, it was investigated whether these 2 fundamental fears would lead to heightened attentional interference by pain on ongoing activities. Cognitive models of fear state that an important function of fear is the early detection of potential threatening situations, and accordingly fear is accompanied by vigilance or heightened awareness of possible sources of threat. ${ }^{13}$ Because IS represents a fearfulness for illness and injury, people with high levels of IS might be prone to prioritize signals of potential injury and show more disruption of ongoing activities when confronted with a pain signal. AS might also be associated with increased attention toward pain. It has been speculated that a defining feature of $A S$ is an increased awareness of bodily sensations in general, ${ }^{17}$ and indeed a selective attentional bias for physical threat words was found in pain-free volunteers scoring high on AS. ${ }^{18}$ Moreover, back pain patients with high AS are reported to experience greater cognitive disruption in response to pain. ${ }^{1}$
The attentional interference effect of pain can be experimentally established with the so-called primary task paradigm, in which participants perform an attentiondemanding task, while at some points pain stimuli are administered. ${ }^{12}$ The critical parameter is deterioration of performance during pain. For the present study we used the primary task as adapted by Crombez et al, ${ }^{7}$ in which participants perform a simple tone discrimination task, while they are occasionally distracted by low intensity nonpainful electrical stimulation. With this paradigm, it was demonstrated that in clinical and nonclinical populations the degree of interference is determined by the intensity, the novelty, the predictability, and the threat value of the stimulus. ${ }^{4-8,10}$ Because threat appraisal is one of the determining features of attentional interference, those who amplify threatening somatic information are expected to show increased attentional interference. ${ }^{8}$ Indeed, persons with high levels of pain-related fear and persons who score high on pain catastrophizing exhibited larger attentional interference than those who were low in pain-related fear and pain catastrophizing. ${ }^{8}$

Extending these findings to AS and IS, it can thus be expected that the presence of these traits might enhance the threat value of somatic stimuli, thereby resulting in larger disruption on attention as well. Persons who are high in IS might amplify the threat value because they perceive the somatic stimuli as signallers of injury, whereas persons who are high in AS might do this because they generally interpret bodily sensations negatively. In addition, both AS and IS are found to be closely related to pain catastrophizing and fear of pain (Vancleef et al, submitted for publication). We therefore hypothesized in the present study that the degree of attentional interference by low intensity electric stimulation is dependent on participants' level of AS and IS. Furthermore, we attempted to replicate previous findings concerning the association between pain catastrophizing and attentional interference.

\section{Materials and Methods}

\section{Participants}

Forty-eight healthy participants (12 men; 36 women) with a mean age of 21.75 years (range, 18 to 43 years; standard deviation, 4.36) took part in this study. All participants were recruited at Maastricht University's local community through advertisements in the university paper and posters in the university building. Inclusion criteria for participation were a good state of health (free from chronic pain symptoms, free from mental illness) and good hearing abilities. All participants gave informed consent and received financial compensation for their participation. Participants were informed that they could decline to participate at any given time during the experiment. Two participants were excluded from the visual analog scale analysis because of missing preexperimental data. The Ethics Committee of the Academic Hospital Maastricht/Maastricht University approved the research protocol. 


\section{Self-report Measures}

Pain catastrophizing was assessed with the Dutch version of the Pain Catastrophizing Scale (PCS). ${ }^{30}$ In this $13-$ item scale, respondents indicate on a 5-point scale to what extent they experience each of 13 feelings and thoughts when they experience pain (eg, "I feel as if I can't take this anymore") Both the original and the Dutch versions of the PCS have proved to be reliable and valid measures. ${ }^{28,33}$

The Dutch version of the Sensitivity Index (SI) ${ }^{31}$ consists of 3 subscales (Anxiety Sensitivity Index [ASI], Injury/ IIIness Sensitivity Index [ISI], and Fear of Negative Evaluation Scale [FNE]). (The English version of the SI was translated into Dutch in a state-of-the-art manner, involving back translation, after which the item content was checked against the original content. The Dutch version of the $\mathrm{SI}$ is available from the corresponding author.) The ASI includes 16 items concerning the negative consequences of experiencing anxiety (eg, "It scares me when my heart beats rapidly"). The ISI ${ }^{31}$ contains 6 items pertaining to the fear of illness (eg, "I get scared when I think I'm coming down with an illness") and 5 items referring to the fear of injury (eg, "The thought of injury terrifies me"). The FNE ${ }^{20}$ consists of 12 items measuring the fear of negative evaluation (eg, "I worry about what kind of impression I make on people"). Participants indicate their degree of agreement with all statements of the SI on a 5-point Likert scale. Psychometric properties of both the original and the Dutch versions of the SI are satisfactory ${ }^{31}$ (Vancleef et al, submitted for publication), with internal consistencies in the Dutch version of .88 (ISI), .84 (ASI), .96(FNE), and .94 (whole SI). The test-retest reliability coefficients for the Dutch version of the SI showed intraclass correlation coefficients ranging from .60 to .64 with a 6-month test interval. Furthermore, the psychometric properties of the $\mathrm{ASI}^{23,26,27}$ the $\mathrm{FNE}^{14,20}$ and recently the $\mid \mathrm{SI}^{3}$ separately have been well documented.

Two visual analog scales were administered before and after the experimental phase, on which participants rated the unpleasantness and the experienced intensity of the electrical stimulation (ES). These scales consisted of a horizontal line $(10 \mathrm{~cm})$ representing a continuum, ranging from "not at all unpleasant/not at all intense" to "very unpleasant/very intense." Participants marked the line at the position within this continuum that reflects their opinion/experience concerning unpleasantness and intensity of the ES.

\section{Auditory Discrimination Task}

In the auditory discrimination task, high $(1000 \mathrm{~Hz})$ and low $(250 \mathrm{~Hz})$ pitch tones (duration, 200 milliseconds [ms]) were presented through a headset to the participants. Participants responded to the tones by pressing a button of a two-buttoned console with their dominant hand. A total of 48 tones were presented, with an interstimulus interval between 1200 and 1800 ms (mean, $1500 \mathrm{~ms}$ ). Half of the tones presented were high in pitch.

\section{Electrical Stimulation}

The ES was delivered by a constant current stimulator (IDEE, Maastricht University) with an internal frequency of $50 \mathrm{~Hz}$. The ESs all had an instantaneous rise and fall time and a duration of 1500 ms. The stimulation was delivered through one pair of $\mathrm{Ag} / \mathrm{AgCl}$ electrodes, filled with hypertonic gel (Spectra EEG gel, Parker Laboratories, INC, NJ), and an inter-electrode distance of $1 \mathrm{~cm}$. The electrodes were attached at the underarm of the nondominant arm, after the skin area beneath the electrodes was first rubbed with peeling gel to reduce skin resistance. The ESs all had an intensity of $0.8 \mathrm{~mA}$. In a pilot study, this intensity was found to be well noticeable, although it remained under the pain threshold for all participants.

\section{Procedure}

\section{Pre-experimental Phase}

Participants were tested individually after informed consent was obtained. They were kept unaware of the true nature of the experiment to control for possible demand characteristics. In line with previous studies by Crombez et al, ${ }^{7,8}$ participants were led to believe that they took part in a study that attempted to investigate the putative influence of distracters on a psychophysiologic measure of stimulus perception, whereby the electrodes were used to measure electrodermal activity.

\section{Experimental Procedure}

First, the participants were familiarized with the ES. Therefore, a series of ESs with increasing intensity $(0.2$ to 0.4 to 0.6 to $0.8 \mathrm{~mA}$ ) was administered through the attached electrodes. In this familiarization phase, each ES intensity was only presented once to the participant. Participants were kept ignorant with respect to which of these intensities they would receive in the experimental phase. After this series of ESs, participants rated the unpleasantness and the perceived intensity of the last received ES, which corresponded to the intensity of the ES that would be used throughout the experiment. Next, participants practiced the auditory discrimination task without distracters. The tones (15 low pitch and 15 high pitch) were presented randomly, with an interstimulus interval between 1200 and 1800 ms (mean, 1500 ms). Finally, participants received further instructions about the progress of the experiment. They were told that the primary goal of the study was to investigate the influence of an unfamiliar, painful stimulus on electrodermal activity. Following Crombez et al, ${ }^{8}$ we enhanced the threat value of the ES by providing intrinsically threatening somatic information concerning the ES through telling participants that the ES would directly stimulate pain fibers. In addition, we told participants that in prior studies, the reactions to ES varied across persons, with some persons judging them as very painful, whereas others did not. Finally, participants were instructed that they should try to ignore the pain stimuli and concentrate on performing the auditory task as well and as fast as possible. 
Table 1. Mean Reaction Times (Standard Deviations [SDs]) on Baseline Tone Trials, Experimental Tone Trials, and Interference Scores Separately for the 3 Blocks $(N=48)$

\begin{tabular}{rcll}
\hline & $\begin{array}{c}\text { BASELINE MEAN } \\
\text { REACTION TIME } \\
(\text { SD) }\end{array}$ & \multicolumn{1}{c}{$\begin{array}{c}\text { EXPERIMENTAL } \\
\text { TIME (SD) }\end{array}$} & $\begin{array}{c}\text { MEANTERFERENCE } \\
\text { MED) }\end{array}$ \\
\hline 1 & $460.31(88.44)$ & $543.89(115.70)$ & $83.58(73.94)$ \\
2 & $436.17(78.45)$ & $488.16(115.68)$ & $52.00(71.57)$ \\
3 & $430.78(78.04)$ & $466.88(94.64)$ & $36.10(58.51)$ \\
Total & $442.42(82.22)$ & $499.64(113.15)$ & $57.22(70.69)$ \\
\hline
\end{tabular}

When all these preparation phases were fulfilled, the experimental phase began. This phase consisted of 3 identical blocks that were presented to the participant in a serial order without pauses in between. Each block consisted of $8 \mathrm{ES}$ trials that all had duration of $1500 \mathrm{~ms}$ and a fixed intensity of $0.8 \mathrm{~mA}$. Half of the ES trials (4 trials) were combined with the presentation of a tone. In 2 of these, the tone was presented at 250 ms after onset of the ES, whereas in the other 2 ES trials, the tone was presented at $750 \mathrm{~ms}$ after ES onset. These 2 times of tone presentations ( 250 versus $750 \mathrm{~ms}$ ) were chosen following Crombez et al, ${ }^{5,6}$ who showed that the distractive influence of the ES was most pronounced when a reaction was expected at pain onset (ie, $250 \mathrm{~ms}$ ). Four ES trials without a combined tone were inserted to avoid the ES becoming predictive of a tone. The amount of tones that preceded an ES varied between 4 and 6 (mean, 5). Over the 3 blocks, a total of 144 tones were presented (48 tones in each block), of which half were high in pitch. No more than 3 consecutive trials consisted of a tone with the same pitch. The computer registered reaction times and errors while the participant executed the experiment.

\section{Postexperimental Phase}

Immediately on finishing the experimental phase, participants rated once again the unpleasantness and the experienced intensity of the last presented ES and completed the self-report measures (PCS, SI). The self-report measures were administered after the experimental procedure to avoid demand characteristics. Presenting the questionnaires before the experimental procedure might result in transparency of the research aims as studying pain processes, thereby affecting the task performance of the participants in an undesirable manner.

\section{Results}

\section{Interference Effect}

The overall percentage of errors during the task was $1.5 \%$, with a total of 12 errors $(2.1 \%)$ occurring during the electrocutaneous stimuli and 90 errors (1.4\%) on the stimuli that were not presented during a shock. Only 0.6 $\%$ of the reaction times were missing or invalid. In accor- dance with Crombez et al, ${ }^{6}$ invalid reaction times were defined as reaction times below 150 ms or above 2000 ms.

The mean reaction times and their standard deviations on trials within or outside an ES are depicted in Table 1. We calculated baseline reaction times as the average of reaction times on tones occurring outside an experimental event and experimental reaction times as the average of reaction time scores on the tones falling within the duration of an ES. Interference scores were calculated as the change score in reaction time from the baseline scores to the experimental scores. These interference scores are used in the following analyses and should be interpreted as the mean deterioration on task performance, caused by the ES.

A $2 \times 3$ repeated-measures analysis of variance with Condition (Baseline versus Experimental) as withinsubjects factor and Block (Block 1 versus Block 2 versus Block 3) as between-subjects factor resulted in a main effect of Condition $\left(F_{1,141}=100.95, P<.001, \eta^{2}=.42\right)$ and a main effect of Block $\left(F_{2,141}=4.54, P<.05, \eta^{2}=\right.$ $.01)$. The main effect of Condition indicates that participants responded faster on the baseline tone trials than on the trials within electrical stimulation (Table 1). The main effect of Block shows that participants became faster in their responses throughout the experiment, with the slowest responses in Block 1 (mean, 466.19; standard deviation, 72.75), faster responses in Block 2 (mean, 439.63; standard deviation, 11.58), and the fastest responses in Block 3 (mean, 431.84; standard deviation, 11.24). The Condition $\times$ Block interaction was significant as well $\left(F_{2,141}=6.00, P<.01, \eta^{2}=.08\right)$, indicating that interference was the highest in the first block (Table 1).

To explore a possible effect of time of tone presentation (250 or $750 \mathrm{~ms}$ after onset ES), interference scores for the tones at $\mathbf{2 5 0} \mathrm{ms}$ after ES onset and the interference score for tones at 750 ms after ES onset were calculated separately (Table 2 ).

A $2 \times 3$ analysis of variance with Time (250 versus 750 ms) as within-subjects factor and Block (1 versus 2 versus 3) as between-subjects factor revealed a main effect of Block $\left(F_{2,141}=6.05, P<.01, \eta^{2}=.09\right)$ and a significant interaction between Time and Block $\left(F_{2,141}=4.78, P<\right.$ $\left..05, \eta^{2}=.06\right)$. No main effect for Time $\left(F_{1,141}=.553\right.$, not

Table 2. Mean Interference Scores and Standard Deviations (SDs) for the Tones at 250 Milliseconds After Electrical Stimulation Onset and at 750 Milliseconds After Electrical Stimulation Onset in the 3 Blocks ( $\mathrm{N}=48)$

\begin{tabular}{|c|c|c|c|c|}
\hline \multirow[b]{2}{*}{ BLOCK } & \multicolumn{2}{|c|}{ INTERFERENCE 250} & \multicolumn{2}{|c|}{ INTERFERENCE 750} \\
\hline & MEAN & $S D$ & MEAN & $S D$ \\
\hline 1 & 108.73 & 114.19 & 55.05 & 94.71 \\
\hline 2 & 43.54 & 88.27 & 60.45 & 93.51 \\
\hline 3 & 25.97 & 72.56 & 39.32 & 96.43 \\
\hline
\end{tabular}


Table 3. Bivariate Pearson Correlation Coefficients Between the Interference Scores and the Self-report Measures $(N=48)$

\begin{tabular}{lcccc}
\hline & INTERFERENCE & PCS & ASI & ISI \\
\hline PCS & $.326^{*}$ & & & \\
ASI & .191 & $.606^{\dagger}$ & & \\
ISI & .044 & $.486^{\dagger}$ & $.668^{\dagger}$ & \\
\hline
\end{tabular}

Abbreviations: PCS, Pain Catastrophizing Scale; ASI, Anxiety Sensitivity Index; ISI, Injury/llness Sensitiviy Index.

$* P<.05$.

$+P<.01$

significant) was found. Post hoc analyses with paired $t$ tests showed an effect of Time in the first block only $(t(47)=2.59, P=.013, d=.27)$, indicating a higher interference score at the 250-ms time than at the $750-\mathrm{ms}$ time. No time of tone effects could be identified in block 2 or block 3 .

\section{Association Between the Questionnaire Scores and the Interference Effect}

In the current sample, the mean PCS score was 14.17 (standard deviation [SD], 7.83). The mean scores for the ASI, the ISI, and the FNE were 27.19 (SD, 7.05), 23.92 (SD, 8.34), and 27.39 (SD, 9.86), respectively. (Because the FNE scale was not of interest in the current study, this measure was ignored in further analyses.)

The association between the self-report questionnaires and the mean interference score over the 3 blocks was explored by calculating bivariate Pearson correlation coefficients (Table 3 ). The correlations showed a significant correlation between the interference score and the PCS $(r(48)=.326, P=.024)$, whereas the ASI $(r(48)=$ .191 , not significant) and the ISI $(r(48)=.044$, not significant) did not correlate significantly with the interference scores. (One-way analysis of variance on the interference score, with the median-split scores on the questionnaires as between-subjects factor, revealed a significant group effect of pain catastrophizing as well $\left[F_{1,46}=4.16, P=.047\right]$, but no group effects for the AS or IS were found.) Furthermore, Table 3 shows the correlations between the different measures used in this study. All measures correlated significantly with each other. The highest correlations existed between ASI and ISI ( $r$ $(48)=.668, P<.01)$ and between ASI and PCS $(r(48)=$ $.606, P<.01)$.

\section{Subjective Responses to ESs}

Participants rated the intensity and the unpleasantness of the last experienced ES once after the familiarization with the ES and once again after the experimental procedure. Table 4 shows that these subjective responses were both rated higher before the experimental event than after the experimental procedure. Paired $t$ tests comparing the pre-experimental scores with the postexperimental scores did indeed result in significant differences for both intensity $(t(45)=5.27, P<.001, d=.61)$ and unpleasantness $(t(45)=5.04, P<.001, d=.51)$ ratings.

A possible association between the scores on the visual analog scales and the questionnaire scores was explored with correlational analyses. None of these correlations reached significance, with correlation coefficients ranging between .03 and .23 .

\section{Discussion}

The present study looked into the interruptive nature of pain on attention with the primary task paradigm. It was examined whether IS, AS, or pain catastrophizing affect the degree to which a somatic threatening stimulus distracts attention from the performance on a simple cognitive task in pain-free volunteers.

Results confirmed previous findings concerning the disrupting function of pain on attention. ${ }^{5,7-9,11,12}$ The administration of a somatic threatening stimulus (the ES) caused task deterioration on tone trials that fell within an ES, indicating that the sudden experience of this stimulus drew on the attentional resources of our participants. In addition, we could replicate the finding that attentional interference is larger at the onset of the ES, because interference scores were larger when a response was required at $250 \mathrm{~ms}$ after ES onset, in comparison to a required response at $750 \mathrm{~ms}$ after onset. On the basis of conditioning principles ${ }^{22}$ and cognitive motivational

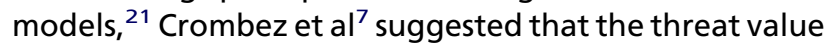
of a stimulus primes the attentional system of the individual, thereby disrupting task performance. Attention will then be switched to the somatic threatening stimulus, which is subsequently evaluated with respect to its meaning and gravity. When this evaluation results in a nonthreatening appraisal of the stimulus, the individual will pursue the activities that were interrupted by pain onset. The difference in interference at 250 and $750 \mathrm{~ms}$ after ES onset applies to the first test block only, which is in agreement with previous findings. ${ }^{5,6}$ Possibly, the easy nature of the auditory discrimination task is responsible for the fact that, even though the ES keeps slowing down reaction times, the strongest initial influence of pain declines when the participant is more familiarized with the task procedure.

The current study further confirmed the previous finding that individual differences in pain catastrophizing influence attentional interference scores. ${ }^{8,10}$ High scores

Table 4. Pre-experimental and Postexperimental Mean Visual Analog Scores on Experienced Intensity and Unpleasantness $(\mathrm{N}=46)$

\begin{tabular}{|c|c|c|c|c|}
\hline & \multicolumn{2}{|c|}{ PRE-EXPERIMENTAL } & \multicolumn{2}{|c|}{ POSTEXPERIMENTAL } \\
\hline & MEAN & $S D$ & MEAN & $S D$ \\
\hline Intensity & 51.23 & 21.61 & 33.28 & 20.71 \\
\hline Unpleasantness & 48.00 & 25.12 & 31.02 & 22.27 \\
\hline
\end{tabular}


on the pain catastrophizing scale were associated with larger task deterioration on the auditory discrimination task. We were, however, unable to demonstrate a likewise influence of either IS or AS on task deterioration. The correlations between the interference scores and the fundamental fear constructs were small, indicating that the presence of these traits does not influence the allocation of attentional processes. Therefore, it seems appealing to conclude that the hypothesized amplifying effect of both IS and AS on the threat value of the ES does not exist. However, some alternative explanations for the lack of finding our hypothesized effect should be taken into consideration. With respect to IS, the lack of ecologic validity might be responsible for the low correlations with the interference effect. IS is related to general negative expectations and anticipations of putative future injury and illness. In the current study, participants were aware that they were taking part in a controlled study in which intensity and duration of the used stimuli were limited (in comparison to real-life situations), thereby not likely resulting in serious tissue damage. Consequently, the anticipative fear of possible longterm health complaints is not realistically present in this experimental setup.

With respect to $A S$, it is conceivable that the relation between AS and the interference scores could not be detected because of the nature of the threatening bodily sensations that are caused by the ES. In the definition of AS, a specific sensitivity for the experience of anxiety sensations is stated. ${ }^{25}$ However, in the current study, the ES is externally administered to the person and might not be evaluated as an internally threatening sensation to the participant. In addition, it can be argued that the ES in the current study is not aversive enough to elicit strong general anxiety for the experienced bodily sensations. Indeed, Eccleston ${ }^{11}$ reported the magnitude of the pain intensity as a crucial variable in its effect on attentional awareness. However, Crombez et $\mathrm{al}^{7}$ provided evidence that in a healthy population, the threat of pain (either internal or external), in combination with the novelty and unpredictability of the ES, satisfies the necessary conditions to obtain an enhanced disruption on attention in persons with high levels of pain catastrophizing. $5,7,8,12$ The present results support these findings with respect to pain catastrophizing. Nevertheless, because we failed to assess whether the ESs used in this study were indeed evaluated as unpredictable and threatening to the participants, we cannot fully exclude the possibility that the ESs actually did not possess our intended threat value and unpredictability. Yet it is possible that the primary task paradigm as adapted in the current study provides not enough sensitivity to obtain likewise effects in persons with high levels of AS and IS, because the fundamental fears are less specific and of a higher order than pain catastrophizing is. Further research should address the facet of the sensitivity of the primary task paradigm as it is used in the current setup.

An additional interesting and remarkable finding of the current study concerns the correlations between the questionnaire measures, more specifically the relation between AS, IS, and pain catastrophizing. A prior study showed that although both AS and IS are associated with pain catastrophizing, IS was the strongest predictor for this factor (Vancleef et al, submitted for publication). However, inspection of the correlations between the questionnaire measures in the current sample shows that AS, and not IS, correlates the highest with pain catastrophizing. This might be caused by the time of assessment of the questionnaires. In the current study, all questionnaires were assessed after the experimental procedure, and that might have affected participants' response tendencies. Although AS and IS are both considered as dispositional personality traits, the possibility exists that the specific item characteristics of the measures assessing these traits have an undesirable effect on the eventual scores on these measures. Both the PCS and the ASI possess items that ask directly for experienced pain and experienced bodily sensations. It might therefore be the case that respondents take the pain from the experiment as referent in their mind while filling in the questionnaires, with a resulting high correlation between the 2 measures. The ISI consists of items that are posited in such a way that they refer to the general fearfulness of experiencing injury or illness at some time in the future and is therefore less applicable to the low intensity pain stimulus from the experiment. Comparable findings were recently reported by Thorn et al, ${ }^{32}$ who showed that PCS scores that were assessed before an experimental pain induction did not predict pain intensity ratings, whereas post-PCS scores did. These authors argued that the PCS might measure situational catastrophizing when it is administered after experimental pain stimulation rather than dispositional catastrophizing, which it measures when it is assessed before the experimental pain procedure. Further research should pay attention to state-like properties of particularly the ASI that result from the specific item content of this measure.

Several limitations should be taken into consideration when interpreting the results of the current study. First, one could argue that the rather small sample size $(\mathrm{N}=$ 48 ) is responsible for the lack of finding significant effects for the ASI and the ISI with the interference scores. However, this possibility seems unlikely because the found association between the interference effect and pain catastrophizing does not differ substantially from the effects that Crombez et $\mathrm{al}^{8,10}$ found in earlier studies with resembling sample sizes. Moreover, the strong general interference effect that is found in the current study gives further indication that the failure to find effects with AS and IS is not resulting from sample size problems. Particularly with respect to IS, the correlation with the interference score is so small that an increase in sample size would still not lead to a sufficient high correlation to obtain the hypothesized association. Rather than problems with sample size, however, it is possible that extreme values of AS and IS are required to establish their influence on attentional interference. In the current study, these extreme values are particularly missing for AS. Future research with these factors should consider a 
prior selection on extreme values for these traits to verify this possibility. One could further raise the argument that a clinical research population would have yielded better interpretable results. However, the current study was specifically conducted in a nonclinical population, because it is theorized that both IS and AS are dispositional risk factors in the etiology of acute and chronic pain, being present before pain develops. Putative results of this study can then be assigned to the presence of IS and AS, disentangling their influence from the effect that the actual presence of chronic pain could have on the task performance. Moreover, the measure that assesses IS, the ISI, consists of items that ask for worrying and fearfulness of future injury and illnesses. Therefore, it is unadvisable to administer this measure in a clinical pain population, because their actual pain experience will affect the interpretation and response mode on the questions.

The lack of evidence for an influential role of both AS and IS on attentional interference emphasizes the need for further research in the validation of these concepts and the role they play in pain processing. It is possible that IS is not so much related to attentional interference by pain once it is there, but rather to the interpretation and validation of future injury or illness. Therefore, it might be proposed that the role of IS should be investigated with an interpretation bias paradigm in which the schema of a person concerning several pain-related situations can be investigated.

Despite the negative findings concerning the role of AS and IS, the current study has proved convincingly that pain has the characteristic of demanding attention and that it interferes with other cognitive tasks that have to be fulfilled. Also, this attentional distraction is enhanced in pain catastrophizers, who amplify threatening information and exaggerate the negative consequences of pain. The role of IS and AS in the chronic pain problem needs further attention and research.

\section{References}

1. Asmundson GJG, Norton GR: Anxiety sensitivity in patients with physically unexplained chronic back pain: A preliminary report. Behav Res Ther 33:771-777, 1995

2. Asmundson GJG, Wright KD, Hadjistavropoulos HD: Anxiety sensitivity and disabling chronic health conditions: State of the art and future directions. Scand J Behav Ther 29:100117,2000

3. Carleton NR, Asmundson GJ, Taylor S: Fear of physical harm: Factor structure and psychometric properties of the Injury/IIIness Sensitivity Index. J Psychopathol Behav Assessment 27:235-241, 2005

4. Crombez G, Baeyens F, Eelen P: Sensory and temporal information about impending pain: The influence of predictability on pain. Behav Res Ther 32:611-622, 1994

5. Crombez G, Eccleston C, Baeyens F, Eelen P: The disruptive nature of pain: An experimental investigation. Behav Res Ther 34:911-918, 1996

6. Crombez G, Eccleston C, Baeyens F, Eelen P: Habituation and the interference of pain with task performance. Pain 70:149-154, 1997

7. Crombez G, Eccleston C, Baeyens F, Eelen P: Attentional disruption is enhanced by the threat of pain. Behav Res Ther 36:195-204, 1998

8. Crombez G, Eccleston C, Baeyens F, Eelen P: When somatic information threatens, catastrophic thinking enhances attentional interference. Pain 75:187-198, 1998

9. Crombez G, Eccleston C, Baeyens F, Van Houdenhove B, Van den Broeck A: Attention to chronic pain is dependent upon pain-related fear. J Psychosom Res 47:403-410, 1999

10. Crombez G, Eccleston C, Van den Broeck A, Van Houdenhove B, Goubert L: The effects of catastrophic thinking about pain on attentional interference by pain: No mediation of negative affectivity in healthy volunteers and in patients with low back pain. Pain Res Manag 7:31-39, 2002

11. Eccleston C: Chronic pain and attention: A cognitive approach. Br J Clin Psychol 33:535-547, 1994

12. Eccleston C, Crombez G: Pain demands attention: A cognitive-affective model of the interruptive function of pain. Psychol Bull 125:356-366, 1999

13. Eysenck MW: Anxiety and Cognition: A Unified Theory. Hove, England, Psychology Press/Erlbaum, 1997

14. Garcia Lopez LJ, Olivares J, Hidalgo MD, Beidel DC, Turner SM: Psychometric properties of the social phobia and anxiety inventory, the Social Anxiety Scale for Adolescents, the Fear of Negative Evaluation Scale, and the Social Avoidance and Distress Scale in an adolescent Spanish-speaking sample. J Psychopath Behav Assess 23:51-59, 2001

15. Greenberg J, Burns JW: Pain anxiety among chronic pain patients: Specific phobia or manifestation of anxiety sensitivity? Behav Res Ther 41:223-240, 2003

16. Keogh E, Asmundson GJ: Negative affectivity, catastrophizing and anxiety sensitivity, in Asmundson GJ, Vlaeyen JW, Crombez G (eds): Understanding and Treating Fear of Pain. New York, NY, Oxford University Press, 2004

17. Keogh E, Cochrane M: Anxiety sensitivity, cognitive biases, and the experience of pain. J Pain 3:320-329, 2002

18. Keogh E, Dillon C, Georgiou G, Hunt C: Selective attentional biases for physical threat in physical anxiety sensitivity. Anxiety Disorders 15:299-315, 2001

19. Keogh E, Mansoor L: Investigating the effects of anxiety sensitivity and coping on the perception of cold pressor pain in healthy women. Eur J Pain 5:11-25, 2001

20. Leary MR: A brief version of the Fear of Negative Evaluation Scale. Pers Soc Psychol Bull 9:371-375, 1983

21. Norman DA, Shallice T: Attention to action: willed and automatic control of behaviour, in Davidson RJ, Schwartz GE, Shapiro D (eds): Consciousness and Self Regulation. New York, NY, Plenum Press, 1986, pp 1-18

22. Öhman A: The orienting response, attention and learning: An information-processing perspective, in Kimmel HD, Van Olst EH, Orlebeke JF (eds): The Orienting Reflex in Humans. Hillsdale, NY, Lawrence Erlbaum Associates, 1979, pp 443-471 
23. Peterson RA, Heilbronner RL: The Anxiety Sensitivity Index: Construct validity and factor analytic structure. J Anx Disord 1:117-121, 1987

24. Reiss S: Expectancy model of fear, anxiety, and panic. Clin Psychol Rev 11:141-153, 1991

25. Reiss S, Peterson RA, Gursky DM, McNally RJ: Anxiety sensitivity, anxiety frequency and the prediction of fearfulness. Behav Res Ther 24:1-8, 1986

26. Rodriguez BF, Bruce SE, Pagano ME, Spencer MA, Keller MB: Factor structure and stability of the Anxiety Sensitivity Index in a longitudinal study of anxiety disorder patients. Behav Res Ther 42:79-91, 2004

27. Sandin B, Chorot P, McNally RJ: Anxiety Sensitivity Index: Normative data and its differentiation from trait anxiety. Behav Res Ther 39:213-219, 2001

28. Severeijns R, van den Hout MA, Vlaeyen JWS, Picavet HSJ: Pain catastrophizing and general health status in a large Dutch community sample. Pain 99:367-376, 2002
29. Stewart SH, Conrod PJ, Gignac ML, Pihl RO: Selective processing biases in anxiety-sensitive men and women. Cognition Emotion 12:105-133, 1998

30. Sullivan MJL, Bishop SR, Pivik J: The pain catastrophizing scale: Development and validation. Psychol Assess 7: 524-532, 1995

31. Taylor S: The structure of fundamental fears. J Behav Ther Exp Psychiatry 24:289-299, 1993

32. Thorn BE, Clements KL, Ward LC, Dixon KE, Kersh BC, Boothby JL, Chaplin WF: Personality factors in the explanation of sex differences in pain catastrophizing and response to experimental pain. Clin J Pain 20:275-282, 2004

33. Van Damme S, Crombez G, Bijttebier P, Goubert L, Van Houdenhove $B$ : A confirmatory factor analysis of the Pain Catastrophizing Scale: Invariant factor structure across clinical and non-clinical populations. Pain 96:319324,2002 